\title{
Building A Sustainable Future using Advance Street Lighting System
}

\author{
Er.Rajiv Kumar Bali ${ }^{1}$, Er.Sonam Gupta ${ }^{2}$, Ashish Dogra ${ }^{3}$, Manik Abrol ${ }^{4}$, Akhil Jamwal ${ }^{5}$ \\ Associate Professor ${ }^{1}$, Assistant Professo ${ }^{2}$, Student ${ }^{3,4,5}$ \\ Dept. of Electrical Engg. \\ Govt. College of Engg. \& Technology, Jammu, India \\ iamrajivbali@gmail.com,gupta.sonam162@gmail.com,dograashish1610@gmail.com, \\ manikabrol16h@gmail.com, akhiljamwal143@gmail.com
}

\begin{abstract}
With the advancement in science and technology, electrical energy has become one in every of the essential suggests that to hold out today's life. Power demand affects the lives of people in many ways. With this surge in the demand of power, it is important, rather essential, to find ways to conserve power to prevent resources from getting exhausted. The present paper focuses on one of the solutions for this problem, i.e. by building sensible street lights which can scale back power wastage because of unessential lighting of street lights in spite of traffic density and at odd hour using microcontroller and light dependent sensor for detecting the movement of the objects. The prototype has been designed that will automatically control the street lights at different intensity levels.
\end{abstract}

Keywords- Arduino Uno R3, IR (Infrared) motion sensor, LDR (Light Dependent Resistor), LED (Light Emitting Diode), Resistor.

\section{INTRODUCTION}

The 21 st century is striving hard to save electrical energy. Street lights are essential, but expensive, therefore there is need to optimize the system in a way that it is affordable and efficiently conserves energy. The main problem that manual controls face is that at morning it has been noticed that street lights are still ON when it's not necessary where as there would be a lot time taking during evening times when they are to be switched $\mathrm{ON}$ and a significant waste of energy is done at morning at all could not be turned OFF together at once. Therefore, there is a need to come up with a system which reduces manual control and would efficiently save energy. This could be done by using low power, robust and efficient components. In this scenario, when the street lights are in working functionality over the whole night that consumes a lot of energy and reduces the lifetime of the electrical equipment such as electric bulb etc. Also in cities streetlights, during the non peak hours, the traffic density is quite low but still street lights keep glowing with full intensity. It leads to the wastage of electricity. The main purpose of this project is to minimize the cost \& loss of electricity and also man power to manually on- off the street light. Our objective is to provide a fully automated street light control which will definitely affect mankind. It will provide a public lighting system which is cost effective and can decrease lighting cost upto 70\% [4].

K.Santha Sheela [2] has surveyed on street lighting system based on vehicle movements. The system operates in the automatic mode which controls the street light according to brightness and dimness and light intensity. The whole project was implemented using a PIC microcontroller. S.Suganya [1] has proposed about streetlight glow on detecting vehicle movement using sensor system that utilizes the latest technology for sources of light as LED [13] lamps. It is also used to develop a automatic street light detection system using infrared detection technology. Jerin George [3] has demonstrated an easy and energy efficient streetlight intensity control system which does not need much maintenance. The proposed work is accomplished by ARDUINO [7] microcontroller and sensors for object detection.

\section{PROPOSED SYSTEM COMPONENTS}

The traditional lighting system has been confined to only two options i.e ON and OFF only, and it is inefficient because this kind of operation leads to power loss due to continuing working on maximum voltage. Hence the wastage in the street lighting forms major part of loss in the municipal load. In this system HID [8-10] is used based on principle of gas discharge, thus the intensity is not controlled [13] by any reduction method. The proposed system depends on the detection of vehicle movement using IR SENSORS [6].

Multiple electronic components are used for building electronic circuits. Our proposed circuit designs contain these components that are described below in table 1

Table 1. Specifications of electronic components

\begin{tabular}{|l|l|l|}
\hline S.NO. & Components & Specifications \\
\hline 1. & LDR & Voltage: DC 3-5V, 5mm,1.8 gm. \\
\hline 2. & Arduino Uno & 22 pins, operating voltage 6-20V \\
\hline 3. & LED [13]s & $5 \mathrm{~mm}$, operating voltage 5V \\
\hline 4. & IR sensor & Voltage: DC 3-5V, Range 2-30cm \\
\hline
\end{tabular}




\section{Available online at www.ijrat.org}

\begin{tabular}{|l|l|l|}
\hline 5. & Resistors & $100 \mathrm{ohm}, 220 \mathrm{ohm}$ \\
\hline
\end{tabular}

\section{Microcontroller}

ATmega328 based ARDUINO Uno R3shown in fig. 1 is a series microcontroller which has an IDE (Integrated Development Environment) for writing, compiling and uploading codes to the microcontroller. The operating voltage of microcontroller is at $5 \mathrm{v}$, input voltage 7 to $12 \mathrm{v}$, input voltage limit up to $20 \mathrm{v}$, digital I/O pins 14, analog pins 6, DC current 40mA, flash memory $32 \mathrm{~KB}$ including $0.5 \mathrm{~KB}$ used by boot loader. SRAM of $2 \mathrm{~KB}$, EEPROM of $1 \mathrm{~KB}$ and clock speed of $16 \mathrm{MHz}$ some of the Features of ARDUINO UNO are power: can be USB connection or external power supply, with 7 to 12 volts recommended. The ARDUINO UNO provides power pins for other devices, the variants are $5 \mathrm{~V} 3.3 \mathrm{~V}$ and $\mathrm{Vin} \mathrm{I} / \mathrm{O}, \mathrm{REF}$ pin for optional power [7].

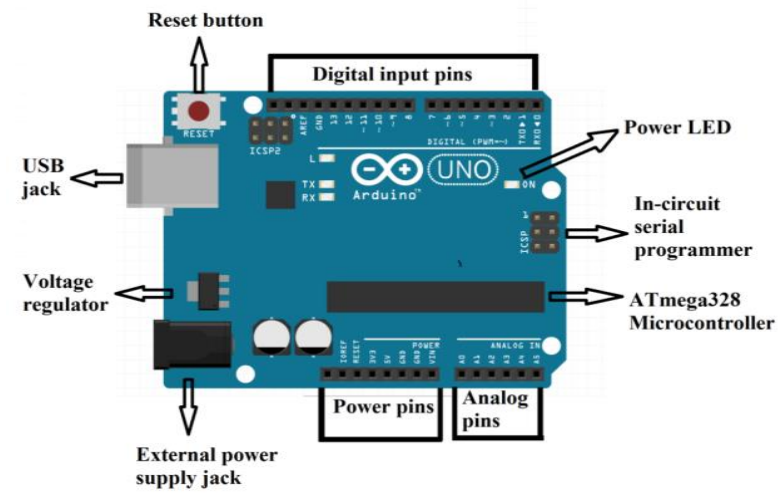

Fig. 1. ARDUINO Uno Board [7]

\section{Infrared sensor}

An infrared sensor is an electronic device that emits in order to sense some aspects of the surroundings. An IR sensor can measure the heat of an object as well as detects the motion. Usually in the infrared spectrum, all the objects radiate some form of thermal radiations as shown in fig.2. These types of radiations are invisible to our eyes that can be detected by an infrared sensor. The emitter is simply an IR LED [13] and the detector is simply an IR photodiode which is sensitive to IR light of the same wavelength as that emitted by the IR LED [13]. When IR light falls on the photodiode, the resistances and thus output voltages, change in proportion to the magnitude of the IR light received.

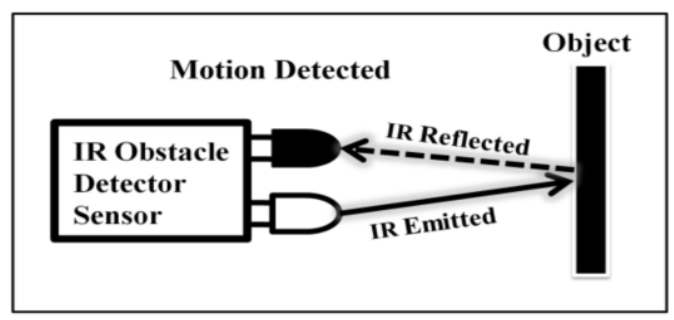

Fig. 2. IR Sensor [6]

\section{Street light (LED)}

This is output of the system given by Microcontroller. A light-emitting diode (LED [13]) is a two-lead semiconductor light source which is made up of InGaN material. It is a pn-junction diode, which emits light when activated. When a suitable voltage is applied to the leads of LED [13], electrons can recombine with electron holes within the device, and release energy in the form of photons.

\section{Light dependent resistor (LDR)}

LDR [5] is a Light Dependent Resistor (Fig. 2a) whose resistance is dependent on the light impinging on it. The resistance offered by the sensor decreases with the increase in light strength and increases with the decrease in light strength. This device is used for detection of day-time and night-time because when sunlight falls on it, it will consider as day-time, and when there is no sunlight falls on it, it will be regarded as a night, as shown in Fig. 2b. These are very beneficial, especially in light/dark sensor circuits and help in automatically switching ON /OFF the street lights [9-12].
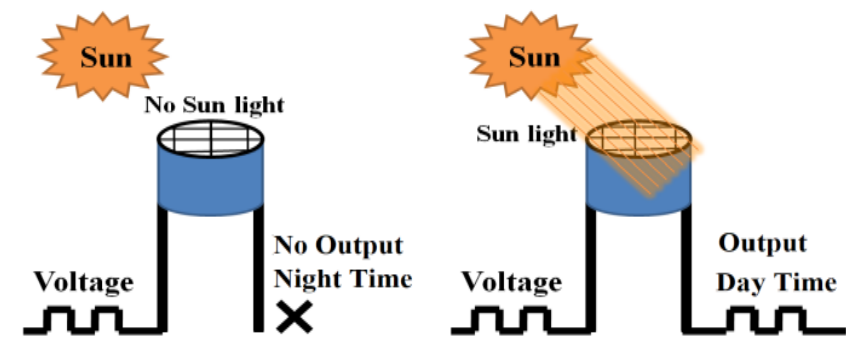

Fig . 3. LDR [10]

\section{METHODOLOGY}

The proposed system depends on the detection of vehicle movement using IR SENSORS [6]. The IR sensor is a proximity sensor which consists of an emitter LED [13] and a receiver LED [13] embedded in it. IR radiation is constantly emitted by the emitter LED [13]. When this radiation is blocked by some metal or reflecting object at a distance, the IR radiation gets reflected by the object can be detected by observing the receiver LED [13].

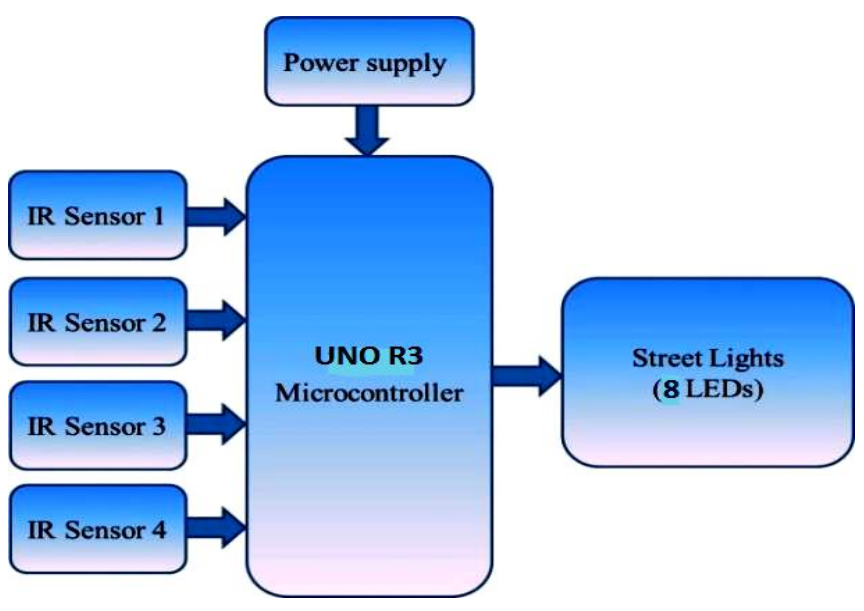

Fig. 4. Block Diagram 


\section{Available online at www.ijrat.org}

This principle can be used to detect vehicles on pedestrians or the on street roads and accordingly switch the successive streetlights to full intensity, as long as the vehicle blocks the IR sensor radiation, fixed to the street light near to the ground. Fig.5 below shows the schematic block diagram.

The resistance of LDR [10] changes in accordance with the intensity of the light falling on it. When high intensity light (sunrays) fall on it it sends signal to ARDUINO [7] which turns OFF the street lights during daytime whereas in absence of light, the output of LDR changes which causes the ARDUINO [7] to turn the lights ON. In the proposed prototype, four IR sensors [6] will detect the object (Presence of vehicles). IR transmitter will transmit IR rays, if any object (vehicle) comes in range of this IR ray then the object will reflect this IR rays which is sensed by IR receiver. When object (vehicle) is detected it will transmit the signal to the Microcontroller.

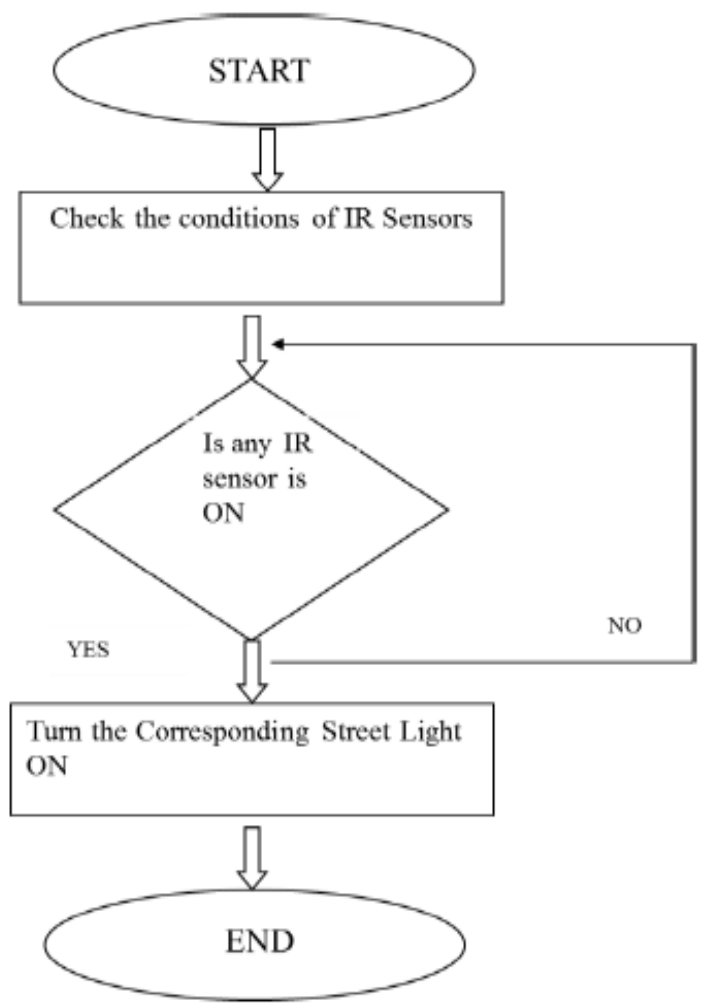

Fig. 5. Flow chart representation

Initially all the LED [13]s will be glowing with dim (less) intensity. When vehicle comes near to the first IR sensor then IR sensor will detect it \& first street light will glow with full intensity \& second, third and fourth street light will glow with dim (less) intensity. As vehicle moves forward, the 2nd IR sensor will detect its presence, consequently second street light will glow with full intensity as well as first, third \& fourth street light will glow with dim (less) intensity. Similarly when vehicle comes near to the 3rd IR sensor, fourth street light will glow with full and first, second \& fourth street light will glow with dim (less) of intensity. At the end, when vehicle comes near to the 4th IR sensor, Fourth Street light will glow with full and first; second \& Fourth Street light will glow with dim (less) intensity. UNO ARDUINO [7] R3 Microcontroller is the most important part of our project. When the object (vehicle) will pass through the Street then the IR SENSORS [6] will detect the object and then it will give the signal to the corresponding pin of the microcontroller. It will receive the signal from IR Sensor, check conditions and process them according to program. After that it will give output and control the street lights. It will give full intensity to the corresponding street light of detected vehicle by IR sensor. The flow chart shown in fig. 6 describes the whole process.

\section{RESULTS \& DISCUSSION}

The hard work and the efforts has been done in this project to reduce the side effects of the previous and current street lighting system used in our area, and to find a solution to save the power. If this project will be implemented on a large scale then it will be very useful and will fulfill all the present constraints. The table2 shows the comparative analysis in terms of cost, time and other relevant specification.

Table 2. Comparative analysis of conventional system and our system.

\begin{tabular}{|c|c|c|c|}
\hline S.no. & Parameters & $\begin{array}{l}\text { Conventional } \\
\text { system }\end{array}$ & $\begin{array}{l}\text { Automatic } \\
\text { light control } \\
\text { different } \\
\text { intensity }\end{array}$ \\
\hline 1. & Initial cost & Low & High \\
\hline 2. & Overall cost & Low & Low \\
\hline 3. & $\begin{array}{l}\text { On-state time } \\
\text { of street light }\end{array}$ & $\begin{array}{l}\text { Manual control } \\
\text { from sunset to } \\
\text { sunrise }\end{array}$ & $\begin{array}{l}\text { Depend upon } \\
\text { presence of object } \\
\text { from sunset to } \\
\text { sunrise }\end{array}$ \\
\hline 4. & Lamps used & fluorescent & LED [13] \\
\hline 5. & $\begin{array}{l}\text { Energy } \\
\text { consumption }\end{array}$ & More & Less \\
\hline
\end{tabular}

Various results obtained after testing for the different conditions from sunset to sunrise of Street lights (LED [13]) corresponding to the status of IR sensor shown in table 3

Table 3. Results of prototype after testing

\begin{tabular}{|l|l|l|l|l|l|l|l|l|l|l|l|l|}
\hline $\begin{array}{l}\text { S.No } \\
\cdot\end{array}$ & $\begin{array}{l}\text { IR } \\
\mathbf{1}\end{array}$ & $\begin{array}{l}\text { IR } \\
\mathbf{2}\end{array}$ & $\begin{array}{l}\text { IR } \\
\mathbf{3}\end{array}$ & $\begin{array}{l}\text { IR } \\
\mathbf{4}\end{array}$ & $\begin{array}{l}\text { LED } \\
\mathbf{1}\end{array}$ & $\begin{array}{l}\text { LED } \\
\mathbf{2}\end{array}$ & $\begin{array}{l}\text { LED } \\
\mathbf{3}\end{array}$ & $\begin{array}{l}\text { LED } \\
\mathbf{4}\end{array}$ & $\begin{array}{l}\text { LED } \\
\mathbf{5}\end{array}$ & $\begin{array}{l}\text { LED } \\
\mathbf{6}\end{array}$ & $\begin{array}{l}\text { LED } \\
\mathbf{7}\end{array}$ & $\begin{array}{l}\text { LED } \\
\mathbf{8}\end{array}$ \\
\hline 1 & 0 & 0 & 0 & 0 & D & D & D & D & D & D & D & D \\
\hline 2 & 1 & 0 & 0 & 0 & F & F & D & D & D & D & D & D \\
\hline 3 & 0 & 1 & 0 & 0 & D & D & F & F & D & D & D & D \\
\hline 4 & 0 & 0 & 1 & 0 & D & D & D & D & F & F & D & D \\
\hline 5 & 0 & 0 & 0 & 1 & D & D & D & D & D & D & F & F \\
\hline
\end{tabular}


where,

0- Object not detected by IR sensor.

1-Object detected by IR sensor.

D- Street light will glow with dim(less) intensity

F- Street light will glow with full intensity

\section{CONCLUSION AND SCOPE}

The project work has been studied and simulated using a uno ARDUINO microcontroller. The programming and interfering of microcontroller also has been learned during the simulation. This project work includes the study of energy saving system in various applications. The design and simulation of Automatic Street light control system was done magnificently. The main advantage of this system is energy saving and reduction in man power. It only requires the initial cost for designing and installation. Hence, this system is very much useful to the society for reducing the usage of conventional energy source (generated by hydraulic power stations). Therefore, if such systems are once implemented on a large scale can bring major reduction in the power consumption produced by street lights. This initiative will help the government and people to save this energy and meet the domestic and industrial needs. The other benefits of the circuit includes that it is a simple circuit, doesn't require constant observation of time and design flexibility.

In addition to this, wireless module can be implemented which will increase the lifespan of system \& helps in detection of fault. Necessary actions could be taken to control the traffic lights, depending on amount of traffic in particular direction. The system can be implemented with few modifications as a source of revenue; as charging station for battery operated vehicles. Moving with the new \& renewable energy sources, this system can be upgraded by replacing ordinary LED [13] modules with the solar based LED [13] modules.

\section{REFERENCES}

[1] S.Suganya, R.Sinduja, T.Sowmiya and S.Senthikumar, streetlight glow on detecting vehicle movement using sensors.

[2] K.Santha Sheela, S.Padmadevi, Survey on street lighting system based upon vehicle movement.

[3] Sindhu.A.M, Jerin George, Sumit Roy, Chandra J, smart street lighting using IR SENSORS .

[4] S. A. E. Mohamed, "Smart street lighting control and monitoring system for electrical power saving by using VANET," Int. J. Commun. Network Syst. Sci., vol. 6, pp. 351-360, 2013.

[5] A. S. Jalan, "A survey on automatic street lightning system on indian streets using ARDUINO," Int. J. Innovative Res. Sci. Eng. Technol., vol. 6, no. 3, pp. 4139-4144, 2017.
[6] G. Benet, F. Blanes, J.E. Simó and P. Pérez, "Using infrared sensors for distance measurement in mobile robots," Rob. Auton. Syst., vol. 40, no. 4, pp. 255-266, 2002.

[7] L. Louis, "Working principle of ARDUINO and using it as a tool for study and research," Int. J. Control Autom. Commun. Syst., vol.1, no.2, pp. 21-29, 2016.

[8] A. Jalan, G. Hoge, S. Banaitkar and S. Adam, "Campus automation using ARDUINO", Int. J. Adv. Res. Electr. Electron. Instrum. Eng., vol. 6, no. 6, pp. 4635- 4642, 2017.

[9] H. Satyaseel, G. Sahu, M. Agarwal and J. Priya, "Light intensity monitoring \& automation of street light control by Iot," Int. J. Innovations Adv. Comput. Sci., vol. 6, no. 10, pp. 34-40, 2017.

[10] A. Rao and A. Konnur, "Street light automation system using ARDUINO uno," Int. J. Innovative Res. Comput. Commun. Eng., vol. 5, no. 11, pp. 16499-16507, 2017.

[11] M. Abhishek, S. A. Shah, K. Chetan and K. A. Kumar, "Design and implementation of traffic flow based street light control system with effective utilization of solar energy," Int. J. Sci. Eng. Adv. Technol., vol. 3, no. 9, pp. 195-499, 2015.

[12] C. Bhuvaneswari, R. Rajeswari and C. Kalaiarasan, "Analysis of solar energy based street light with auto tracking system," Int. J. Adv. Res. Electr. Electron. Instrum. Eng., vol. 2, no. 7, pp. 3422-3428, 2013.

[13] D. K. Rath, "ARDUINO based: Smart light control system," Int. J. Eng. Res. Gen. Sci., vol. 4, no. 2, pp. 784-790, 2016. 